\title{
Cervicofacial and Mediastinum Emphysema Following Dental Intervention
}

\author{
Mehmet Hüsamettin Akküçük', Suat Avcl ${ }^{2}$, Ebru Torun ${ }^{3}$, Hatice Gönüllü ${ }^{1}$ \\ 'Department of Emergency, Alanya Training and Medical Research Center, Başkent University Faculty of Medicine, Antalya, Turkey \\ 2Department of Otolaryngology-Head and Neck Surgery, Alanya Training and Medical and Research Center, Başkent University Faculty of Medicine, Antalya, Turkey \\ ${ }^{3}$ Department of Radiology, Alanya Training and Medical Research Center, Başkent University Faculty of Medicine, Antalya, Turkey
}

\begin{abstract}
Mediastinitis is a clinical case with high mortality and morbidity ratio. Thus, defining the causes beforehand is significantly important. A 65-year-old male patient present to the emergency care unit because of symptoms such as swelling of his face and neck. Crepitation is noted during palpation at the right lateral face and neck of patients, indicating that swelling occurred after medical intervention by the dentist using spray. Emphysema is seen on the face, neck, and mediastinum on X-ray and CT scans. Patients were hospitalized, and parenteral antibiotic therapy was applied in case of the possibility of serious infection, which may occur because of the use of air syringe, causing the permeation of oral flora to the neck and mediastinum via buccal mucosal ruptures during the patient's dental surgery. Because swellings disappeared and the patient did not have fever on the third day of hospitalization, the patient was discharged after oral antibiotics therapy. Physicians working at the emergency care unit will always keep in mind the risk of deep neck infections and mediastinitis occurrence that patients presenting with swelling symptoms on the neck and face may have following dental surgery. (Eurasian J Emerg Med 2015; 14: 148-50)
\end{abstract}

Keywords: Cervicofacial subcutaneous emphysema, complication, dental laser treatment, mediastinitis

\section{Introduction}

Cervicofacial and mediastinal emphysema following the use of dry air spray during dental procedures are rare complications and can result in deep neck infections or mediastinitis causing severe mortality and morbidity (1-4).

\section{Case Presentation}

A 65-year-old male patient presented to the emergency service with a complaint of swelling of his head. The patient was known to have hypertension, and he stated that the swelling had developed on the face and neck after a surgical tooth extraction using air syringes. On physical examination, crepitation at the subcutaneous region of the right side of the cheek was present with palpation. Lung sounds were equally heard at both hemithoraces. Examination of the cardiovascular and other systems was normal. Direct chest/head radiograph of the patient showed subcutaneous emphysema of the neck and right side of the face (Figure 1). No pneumothorax was visible on the chest X-ray scan. For the differential diagnosis and evaluation of the mediastinum, a thorax CT was performed and showed emphysema of the neck and mediastinum without any pneumothorax (Figures 2,3 ). Because the patient's vital signs were stable and the source of emphysema was the oral cavity, intraoral flora can cause mediastinitis together with emphysema by invading towards the neck and mediastinum; hence, the patient was hospitalized and prophylactic IV antibiotics were initiated against the risk of deep neck infection and mediastinitis. The patient did not have fever and an additional problem for 3 days, and he was discharged after regression of the subcutaneous emphysema by oral antibiotic treatment.

\section{Discussion}

In the cases and reviews reported in the literature, it has been observed that the reason for cervicofacial and mediastinal emphysema following dental procedures is the use of high-speed handpiece and air syringes (1-2, 5-7). Seventy-four reports of emphysematous com-

Correspondence to: Mehmet Hüsamettin Akküçük e-mail: hakkucuk@hotmail.com 


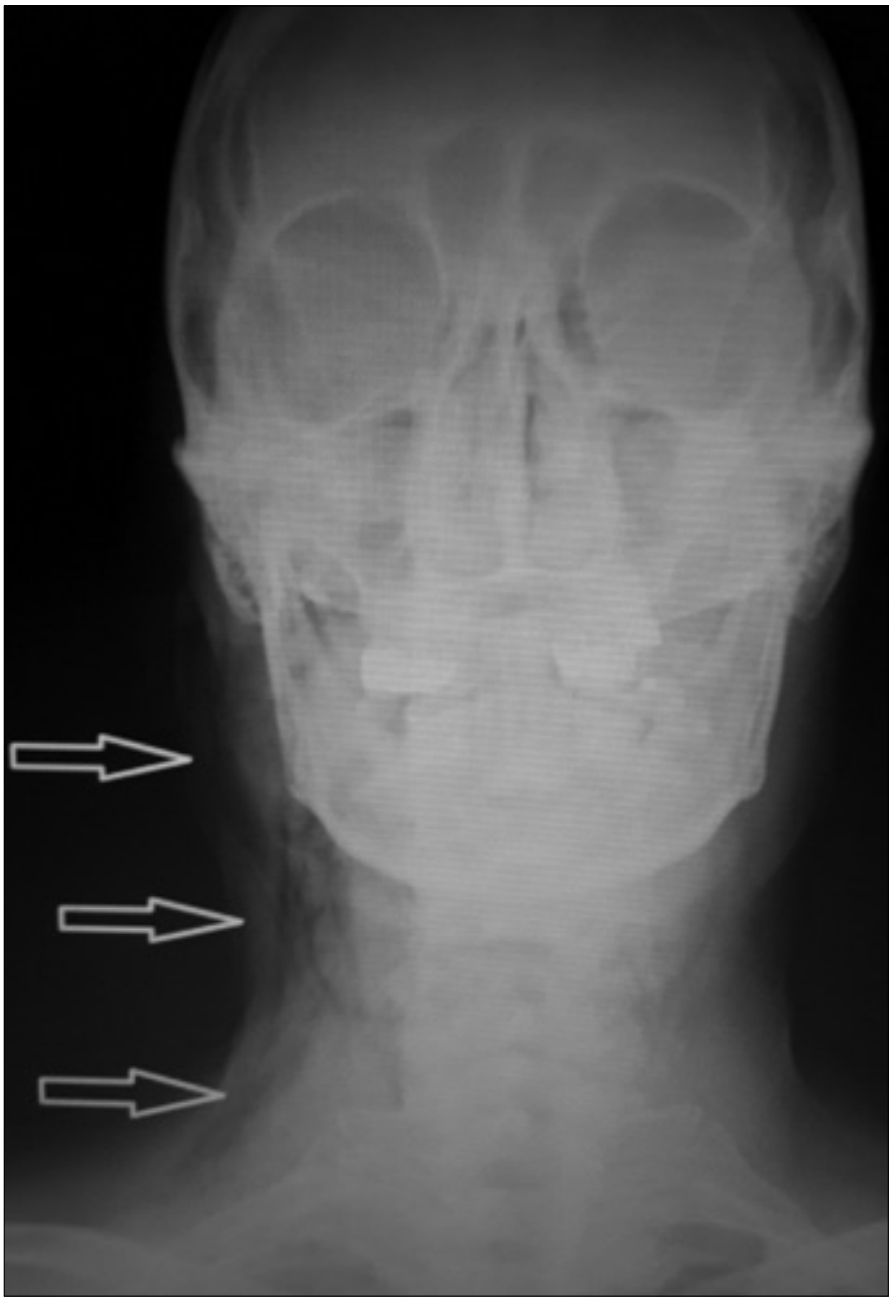

Figure 1. Subcutaneous emphysema of the neck and the right side of the face

plications in ambulatory dental patients have been published in the English literature between 1960 and 1993 (5); in 27 cases, only a highspeed handpiece was used and in 42 patients a high-speed handpiece together with air syringes was used. The other review reported from 1993 to 2008 (1) showed 16 cases of iatrogenic subcutaneous emphysema that were linked to the use of air-driven handpieces. Between 1994 and 2008, 47 CT-documented cases were reported in another review (2); subcutaneous emphysema and pneumomediastinum following dental treatment on using a high-speed air turbine handpiece were seen in 31 patients.

The entrance point of the emphysema is the deep incision made at the buccal mucosa or gingival sulcus and pockets developed after dental procedures (8). Hata and Hosoda (9) reported cervicofacial emphysema caused by $\mathrm{CO}_{2}$ laser therapy for a gingival abscess. Another report (10) described subcutaneous emphysema and pneumomediastinum after the intraoral $\mathrm{CO}_{2}$ laser irradiation of a periapical lesion. Wrong use of dental laser and air projection systems can cause subcutaneous, mediastinal, and cervicofacial emphysema (9, 10). Matsuzawa et al. (11) reported subcutaneous cervicofacial and mediastinal emphysema resulting from a laser incision made for the drainage of a gingival abscess caused by periodontitis. In another case, Mitsunaga et al. (6) diagnosed thoracocervicofacial emphysema caused when an air cooling spray of a dental laser was used. Me-

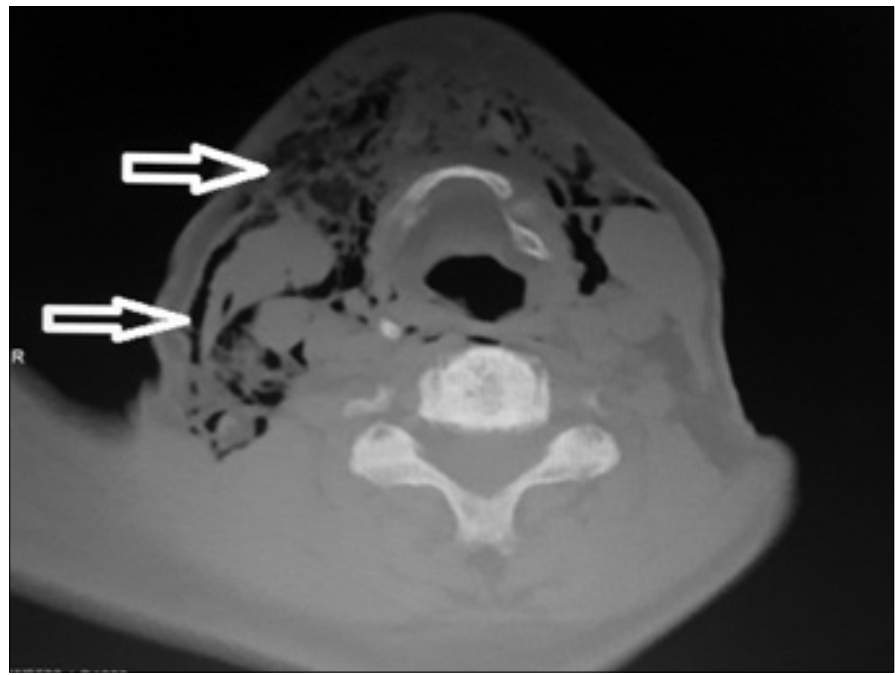

Figure 2. Emphysema of the neck region

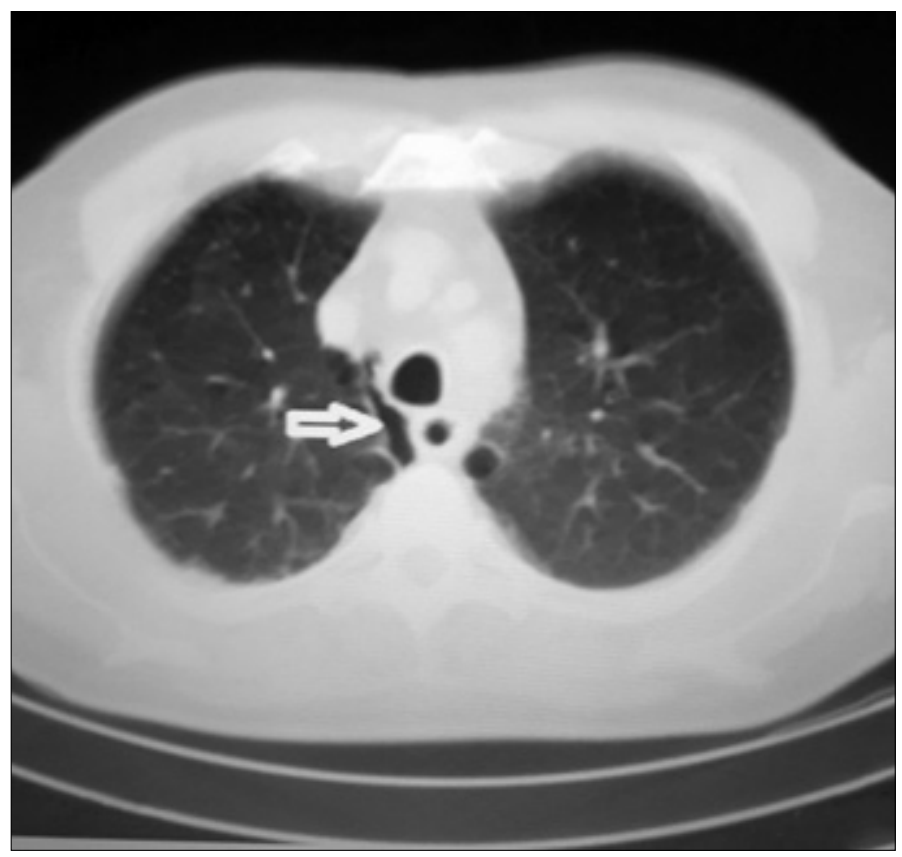

Figure 3. Emphysema of the mediastinum

diastinal emphysema was observed in a majority of patients with cervicofacial emphysema associated with dental laser irradiation (11).

\section{Conclusion}

Cervicofacial and mediastinal emphysema should be considered in patients who present to the emergency department with neck pain and swelling of the face and neck following dental procedures. It should be kept in mind that deep neck and mediastinal infections can develop in these patients and can cause high morbidity and mortality (4-6).

Informed Consent: Written informed consent was obtained from the patient who participated in this case.

Peer-review: Externally peer-reviewed. 
Conflict of Interest: No conflict of interest was declared by the authors.

Financial Disclosure: The authors declared that this study has received no financial support.

\section{References}

1. McKenzie WS, Rosenberg M. latrogenic subcutaneous emphysema of dental and surgical origin: a literatüre review. J Oral Maxillofac Surg 2009; 67: 1265-8. [CrossRef]

2. Arai I, Aoki T, Yamazaki H, Ota Y, Kaneko A. Pneumomediastinum and subcutaneous emphysema after dental extraction detected incidentally by regular medical checkup: a case report. Oral Surg Oral Med Oral Pathol Oral Radiol Endod 2009; 107: e33-8. [CrossRef]

3. Sood T, Pullinger R. Pneumo mediastinum secondary to dental extraction. Emerg Med J 2001; 18: 517-8. [CrossRef]

4. Capecchi M, Buongiorno V, Romagnoli A, Parri SN, Guiducci GM, Bressan E. Severe descending mediastinitis after routine dental implant surgery: a case report. Eur J Oral Implantol 2012; 5: 389-96.

5. Heyman SN, Babayof I. Emphysematous complications in dentistry, 1960-1993: an illustrative case and review of the literature. Quintessence Int 1995; 26: 535-43.
6. Mitsunaga S, Iwai T, Aoki N, Yamashita Y, Omura S, Matsui Y, et al. Cervicofacial subcutaneous and mediastinal emphysema caused by air cooling spray of dental laser. Oral Surg Oral Med Oral Pathol Oral Radiol 2013; 115: e13-6. [CrossRef]

7. Uehara M, Okumura T, Asahina I. Subcutaneous cervical emphysema induced by a dental air syringe: a casereport. Int Dent J 2007; 57: 286-8. [CrossRef]

8. Kim Y, Kim MR, Kim SJ. latrogenic pneumomediastinum with extensive subcutaneous emphysema after endodontic treatment: report of 2 cases. Oral Surg Oral Med Oral Pathol Oral Radiol Endod 2010; 109: e114-9. [CrossRef]

9. Hata T, Hosoda M. Cervicofacial subcutaneous emphysema after oral laser surgery. Br J Oral Maxillofac Surg 2001; 39: 161-2. [CrossRef]

10. Imai T, Michizawa M, Arimoto E, Kimoto M, Yura Y. Cervicofacial subcutaneous emphysema and pneumomediastinum after intraoral laser irradiation. J Oral Maxillofac Surg 2009; 67: 428-30. [CrossRef]

11. Matsuzawa N, Kinoshita H, Shirozu T, Takamura M, Nagao T. Mediastinal emphysema caused by a dental laser. Asian J Oral Maxillofac Surg 2010; 22: 216-9.[CrossRef] 